\title{
TRES VARIACIONES SOBRE EL TEMA DE LA CASA: LEOPOLDO PANERO, LUIS ROSALES Y DULCE MARÍA LOYNAZ
}

\author{
JoAquín JUAN PENALVA
}

\section{1}

Uno de los relatos más completos de esta expedición lo ofrece María del Carmen Díaz de Alda: «El viaje se organizó desde la Dirección General de Relaciones Culturales, cuyo responsable máximo era Ramón Sedol, y fueron invitados -junto con Panero, Zubiaurre y Rosales - Valverde y Gerardo Diego. Valverde desistió porque intuía -según dice'ciertos disgustos y paratazos'; puede ser, aunque no parece suficiente razón, y no debió ser la única; y Gerardo Diego, que por su edad, al final no se decidió, ya que se preveía un viaje con un programa de actividades muy intenso. Fue en un segundo momento cuando se pensó incorporar a Foxá, que era entonces embajador en Argentina y pareció un poeta muy adecuado para este tipo de recitales. / Rosales como poeta consagrado, Zubiaurre que en aquel entonces escribía una extraordinaria poesía, aunque no reunida aún en forma de libro -camino que abandonó prácticamente a partir de 1951 al dedicarse a otros menesteres alejados de la literatura-, Panero, recién llegado del Instituto Español de Cultura de Londres, y Foxá, con toda su aureola de conde y su calidad de diplomático, fueron considerados un grupo idóneo para un viaje de estas características. En primer lugar, eran amigos; todos provenían del Instituto de Estudios Políiticos, lo que aseguraba

Tres variaciones sobre el tema de la casa: Leopoldo Panero, Luis Rosales y Dulce María Loynaz

JOAQUÍN JUAN PENALVA
A finales de 1949 tres poetas peninsulares emprendían una misión poética por tierras hispanoamericanas que les había de deparar, al tiempo que aplausos y calurosas acogidas en algunos países, más de un tomatazo, cuan-

una buena convivencia durante los tres meses previstos para la gira americana, y al prestigio literario unían el tener una cierta representación en la vida política, social e intelectual del país; sobre todo, y creo que éste fue un factor decisivo de cara a la selección de los poetas y a la hora de valorar los resultados, todos ellos eran buenos conocedores (también Valverde lo era) de la cultura hispanoamericana». En María del Carmen Díaz de Alda Sagardía, La poesía de Luis Rosales (desde el inicio a La casa encendida): de la biografía a la poética, Madrid, Universidad Complutense, 1989, pp. 602-603.

\section{2}

Leopoldo Panero invitó al poeta peruano a pasar unas Navidades en Astorga, a lo que éste accedió, de acuerdo con el relato de Ricardo Gullón: «La proclamación de la República y el cambio de régimen produjo en la vida de Leopoldo pocos cambios. Sí los produjo la llegada a Madrid de César Vallejo. Le admiró como poeta y le estimó como hombre. Hablaba de Vallejo con entusiasmo $y$, un día, convocado por él, fui a la tertulia de la Granja El Henar, calle de Alcalá, donde el poeta peruano pasaamigos y correligionarios adoctrinándoles a su manera. Oscuro de tez, boca grande, vestido correctamente de gris y rocado con un sombrero de fieltro que no se quitó en el tiempo que permanecimos en el café, Vallejo habló poco y no pareció tan extraordinario como yo suponía. Lo mejor suyo, sin duda, estaba en la poesía. En Navidad, Leopoldo le llevó a Astorga. Vivió tres días en casa de los Panero y después se instaló por algún tiempo en la casa de huéspedes de la Morla». En Ricardo Gullón, La juveniud de Leopoldo Panero, León, Diputación Provincial de León, 1985, pp. 63-64.

3

Leopoldo Panero, Antología de la poesía hispanoamericana. Desde sus comienzos hasta Rubén Darío. Tomo I, Madrid, Editora Nacional, 1944; Antología de la poesía hispanoamericana. Desde Rubén Darío hasta nuestros días. Tomo II, Madrid, Editora Nacional, 1945.

\section{4}

Luis Rosales, La poesía de $\mathrm{Ne}$ ruda, Madrid, Editora Nacional, 1978. ba largas horas rodeado de do no contundentes patatazos o verdaderas ensaladas arrojadizas, en otros. Los protagonistas de aquel intrépido episodio fueron Luis Rosales, Leopoldo Panero y Antonio de Zubiaurre, a quienes se unió el ingenioso Agustín de Foxá, por aquellas calendas embajador en Argentina. La polémica estaba servida, pues aquellos vates eran, en realidad, los representantes de la cultura oficial del régimen de Franco en unos años en que éste todavía no había recibido el placet internacional. Dos de esos autores, Rosales y Panero, acababan de publicar sendas obras de madurez en las ediciones del Instituto de Cultura Hispánica, concretamente en la colección «La encina y el mar»: La casa encendida y Escrito a cada instante. Esos libros - la fecha del colofón de ambos era el 26 de mayo de 1949- viajaron en sus maletas y les sirvieron como materia poética para los recitales ${ }^{1}$. No era la primera vez que estos poetas, dos de los miembros de la generación del 36 que permanecieron en España tras la contienda y pertenecientes a lo que se ha venido llamando el grupo de la revista Escorial, se interesaban por Hispanoamérica. Así, Panero había colaborado en el primer número de Caballo verde para la poesía (1935), la revista de $\mathrm{Ne}$ ruda; había sido amigo de César Vallejo ${ }^{2}$ en su etapa madrileña, e incluso había editado una antología de la poesía hispanoamerica$\mathrm{na}^{3}$. Rosales, por su parte, publicó muchos años después un interesante y amplio estudio sobre la poesía del chileno ${ }^{4}$, con quien coincidió en algunas ocasiones, y participó, junto a Panero y otros, en el modesto homena- 
je que al poeta peruano le tributó la revista Espadaña.

Unos años antes de que Rosales y Panero emprendieran su primer viaje por Hispanoamérica, la tercera convidada a este artículo, la poetisa - la preferencia por que se la llame así es de la autora, no mía- Dulce María Loynaz, cubana, había comenzado su actividad editorial en España con la publicación en $\mathrm{Ma}$ drid de Juegos de agua, de 1946. Ese mismo año se había casado con Pablo Álvarez de Cañas, periodista de origen canario, $y$, a partir de entonces, pasaría largas temporadas en la capital española, donde había montado una casa. Quiero suponer que Rosales y Panero ya conocían a Loynaz de sus prolongadas estancias madrileñas, cuando participó en un buen número de recitales poéticos, lo que explicaría que la autora actuara como anfitriona en el momento en que la expedición poética pasó por La Habana. Según informa Díaz de Alda, «Panero, Rosales, Foxá y Zubiaurre intervinieron en diversos actos celebrados en el Ateneo, Academia Nacional de Artes y Letras, Lyceum, Lawn T. Club y en la Sociedad Económica de Amigos del País» ${ }^{6}$, siempre bajo la atenta mirada de Loynaz, lo que no evitó, sin embargo, que se organizara toda una campaña de descrédito, orquestada fundamentalmente por Nicolás Guillén y Juan Marinello, contra los poetas españoles. Se llegó a tildar a Rosales de «asesino de Federico», ensañándose en una herida largo tiempo abierta en el granadino. A todos aquellos improperios contestó enérgicamente la propia Loynaz argumentando que ella misma había sido la anfitriona de Lorca en La Habana y en ese momento lo era de aquellos tres autores peninsulares.

Desde el punto de vista meramente anecdótico, este episodio resulta muy interesante, sobre todo porque contamos con los testimonios directos de los protagonistas. Así, el propio Panero lo ha relatado por extenso en el «Ofrecimiento» que precedía a su Canto personal. Carta perdida a Pablo Neruda, libro que le valió la repulsa de propios y extraños y que pretendía ser una contestación al Canto general de Pablo Neruda, aunque el detonante inmediato de la misma hubiera sido el poema «El pastor perdido», incluido en Las wvas $y$ el viento (1952), donde el chileno cantaba a Miguel Hernández y acusaba a José María de Cossío de cenar con sus carceleros ${ }^{7}$. En aquel

"Ofrecimiento" el poeta astorgano manifestaba explícitamente su agradecimiento a algunas personalidades que solícitamente habían atendido a la expedición en cada una de sus estaciones. Entre ellas se encontraba el general Loynaz del Castillo, uno de sus anfitriones cubanos y padre de Dulce María Loynaz: «Quiero agradecer públicamente a La Habana, en la figura del general Loynaz del Castillo y en la fervorosa compañía de Juan Joaquín Otero» ${ }^{8}$.

Con lo expuesto hasta ahora quedan sobradamente justificadas las relaciones personales existentes entre Dulce María Loynaz y los otros dos poetas aquí estudiados: Rosales y Panero. Sin duda, esas mismas relaciones debieron ampliarse cuando la escritora cubana fue nombrada jurado de la Bienal Hispanoamericana de Arte en 19519, el mismo año en que dio a las prensas su única novela, Jardín, publicada en Madrid y estrechamente vinculada al tema de la casa, motivo central del presente artículo. Loynaz también participó en el Segundo Congreso Internacional de Poesía, celebrado en Salamanca en 1953, donde se reunieron un gran número de intelectuales, no sólo españoles, sino europeos e hispanoamericanos.

Ahora bien, no me interesan tanto las relaciones personales como las exclusivamente literarias. Es de suponer que los tres autores estudiados conocieran sus respectivas obras y, por tanto, existe la posibilidad de que entre ellas hubiera influencias mutuas. Coincidien-

5

La publicación leonesa, en su número 39, primero de la etapa de «Poesía Total», incluyó en la contraportada un pequeño recuadro con la siguiente leyenda: «César Vallejo nació el día 6 de junio del año 1893 en Santiago de Chuco (Perú), y murió en París en día 15 de abril de 1938. / José Luis L. Aranguren, Antonio G. de Lama, Victoriano Crémer, Eugenio de Nora, Leopoldo Panero, Luis Rosales, José María Valverde y Luis F. Vivanco le recuerdan". En Espadaña. Revista de poesía y crítica, edición facsimilar, León, Ayuntamiento de León, 1978, p. 800.

6

María del Carmen Díaz de Alda Sagardía, op. cit., p. 605.
7

El estudio más completo sobre la polémica surgida en torno al Canto personal es el de Javier Huerta Calvo: De poética y política. Nueva leciura del Canto personal de Leopoldo Panero, León, Diputación Provincial de León / Instituto Leonés de Cultura, 1996.

8

Leopoldo Panero, Canto personal. Carta perdida a Pablo $\mathrm{Ne}$ ruda, Madrid, Cultura Hispánica, 1953, p. 20.

\section{9}

Panero y Rosales, pero sobre todo Vivanco, formaron parte del comité organizador de las Bienales. La monografía más importante sobre este tema es la de M. Cabañas Bravo, La política
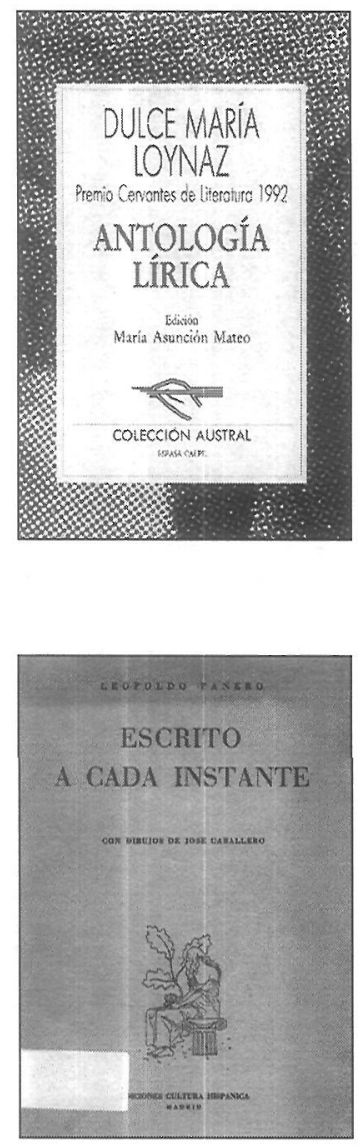

artística del franquismo. El hito de la Bienal Hispano-Americana de Arte, Madrid, C.S.I.C., 1996. También son interesantes los libros de Lorenzo Delgado Gómez-Escalonilla: Diplomacia franquista y política cultural hacia Iberoamérica, 1939-1953 (Madrid, C.S.I.C., 1988) e Imperio de papel. Acción cultural y política exterior en el primer franquismo (Madrid, C.S.I.C., 1992). Luis Felipe Vivanco es el responsable del volumen Primera Bienal Hispanoamericana de Arte (Madrid, Afrodisio Aguado, 1952).

Tres variaciones sobre el tema de la casa: Leopoldo Panero, Luis Rosales y Dulce María Loynaz

JOAQUÍN JUAN PENALVA 

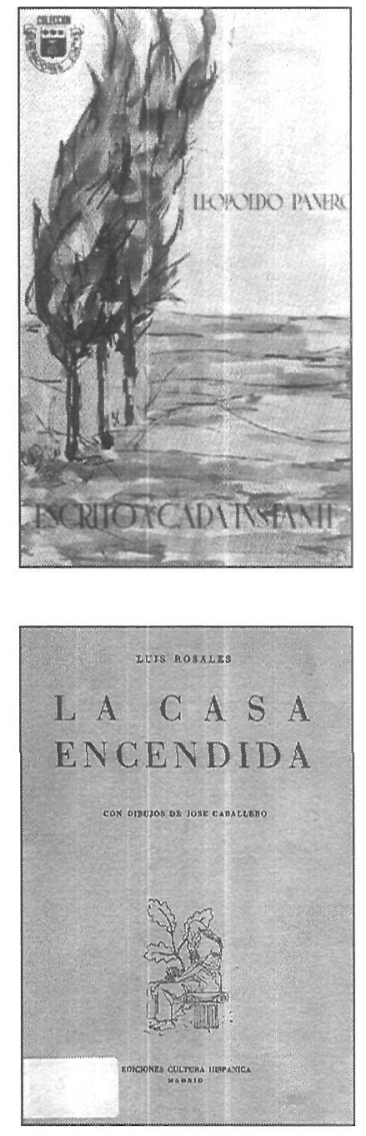

10

Leopoldo Panero, Obras Completas. Volumen II. Prosa, edición de Juan Luis Panero, Madrid, Editora Nacional, 1973, p. 165.

11

Luis Felipe Vivanco, «Aproximándome a la poesía temporal y realista», Proel, VI, primaveraestío de 1950, p. 18.

12

Leopoldo Panero, "La estancia vacía», Escorial. Revista de cultura y letras, núm. 47, tomo XVI, septiembre de 1944, pp. 71108. Durante 1945, las prensas de la revista volvieron a editar el texto de Panero como sobretiro o separata de la publicación.

13

Leopoldo Panero, Obras Completas. Volumen II. Prosa, ed. cit., p. 269.

Tres variaciones sobre el tema de la casa: Leopoldo Panero, Luis Rosales y Dulce María Loynaz

JOAQUÍN JUAN PENALVA do con la aparición de Un verano en Tenerife, un excelente libro de prosa de Loynaz sobre las Islas Canarias, Leopoldo Panero publicó en Blanco y Negro, revista donde se encargaba de la crítica literaria, la reseña titulada «Una isla en la poesía». Salió en noviembre de 1958, apenas un mes antes de la publicación de Últimos días de una casa; en ella el poeta astorgano afirmaba lo siguiente: «Su poesía - varias veces impresa en Madrid- es fuerte, aunque delicada, intensa y nada retórica, desnuda de palabra y de alma, escrita con la sensibilidad en carne viva y con esa misma 'casta desnudez' de que tanto gustaba don Miguel de Unamuno en la fragante poesía juvenil de Juana de Ibarbourou»10. En estas afirmaciones, lo que hay, en realidad, es la definición de la propia poesía de Panero, que se puede hacer perfectamente extensiva a la de Rosales o a la de Vivanco, $y$, en este sentido, no es gratuita la referencia a Unamuno, que, junto a Antonio Machado, Pablo Neruda y César Vallejo, fue uno de los modelos fundamentales de la promoción poética del 36 , a la cual pertenecían todos ellos.

Donde las voces de cada uno de los tres poetas aquí estudiados confluyen de una manera más clara es en La estancia vacía - acaso también en algunos poemas de Escrito a cada instante-, La casa encendida, Últimos dias de una casa y la novela Jardín. Exceptuando la última, que debería ser estudiada aparte y que$\mathrm{da}$, por tanto, proscrita del presente estudio, todas estas obras se insertan dentro de una misma tradición poética. El motivo que las vertebra es el de la casa y, más que de influencias directas, resulta preferible hablar de un aliento común que las impregna. En el caso de los autores del grupo de Escorial, esto se explica perfectamente: parten de unos presupuestos poéticos comunes - Dios, la familia, la religión, lo cotidiano...-, aunque cada uno de ellos los materializa con una voz autónoma $e$ independiente, sin renunciar por eso a una estética común, la del realismo cotidiano o «realismo intimista trascendente» ${ }^{11}$, según la acuñación de Luis Felipe Vivanco. No creo que la poesía de Dulce María Loynaz deba insertarse sin más dentro de esta corriente, aunque su voz poética, al menos en los dos libros aquí mencionados, sí se aproxima lo suficiente a ella como para poder hablar de un espíritu común, alentado por lo pequeño y lo cotidiano de la existencia, teñido en ocasiones de cierto surrealismo - pienso sobre todo en la presencia fantasmal en La casa encendida-.

Me referiré en primer lugar, de manera breve, a los libros de los autores peninsulares, para pasar después a un somero análisis de Últimos días de una casa que permita establecer las diferencias y las semejanzas principales entre este último libro y los anteriores. En orden cronológico, el primer título es La estancia vacía, de Leopoldo Panero, un extenso poema - 1.028 versos - de carácter religiosoexistencial que se publicó por primera vez en el cuaderno 47 de Escorial, correspondiente a septiembre de 194412. Supuestamente se trataba de la primera parte de una composición bastante más amplia, pero Panero nunca la terminó, y los versos aparecidos en la revista madrileña son los únicos que se conservan. Aunque el metro predominante a lo largo de todo el poema es el endecasílabo suelto, $\mathrm{Pa}$ nero inserta entre las largas tiradas algunos sonetos y seguidillas. El propio autor ha señalado el detonante de aquella extensa obra en su conferencia «Unas palabras sobre mi poesía»: «Acababa yo entonces de constituir nuevo hogar y de separarme, por consecuencia, del original y paterno, abandonando para siempre la habitación, la estancia donde habían transcurrido treinta años de mi vida» ${ }^{13}$. El tema de la casa se materializa específicamente en el hogar paterno, concretamente en la habitación donde el joven Leopoldo veló sus armas literarias y compartió inquietudes con su hermano Juan, poeta como él y muerto durante la Guerra Civil. El tema de la soledad, angular en la poética paneriana, queda apuntado desde los primeros versos de la composición:

Estoy solo en la estancia, que se vela de misteriosa claridad vacía, igual que el alma contemplando dentro su propia soledad, su umbral de sombra. $Y$ es éste mi recinto. En lueñe hondura el cielo palidece como el agua en las rocas someras. Lejos, lejos, tenue, profundamente, comprobamos la voluntad de Dios en las estrellas. Señor, ésta es mi casa y mi costumbre. Lejos, sin fin, Te siento. Tras los muros se adivina el olor de las montañas y el olor de los siglos, y la virgen soledad de los astros ensombrece apenas Tu hermosura. Poco a poco 
brota como el rocío el pensamiento que en mi ser Te contiene. Pero el mundo, como el humo, se torna cada noche imperio del olvido.

\section{Señor, ésta}

es mi casa mortal, mi hogar de humo ${ }^{14}$.

Desde el principio se manifiesta la presencia de Dios, que va a simultanearse con la de los objetos cotidianos y con la de los familiares del poeta, principalmente sus padres. Se recuerda en ese momento "la estancia vacía», el despacho, lugar de reflexión y de trabajo, donde Panero conserva recuerdos y objetos cotidianos:

Desamparadamente, contra el cierzo, susurran las acacias.

\section{Lejos, cerca,}

flota una luz secreta entre las cosas cotidianas: la mesa en que trabajo y sueño; la ciudad tras los cristales; los libros en montones de silencio; el trágico confín de cada día; el íntimo desdén de cuanto somos. Flota una luz secreta, entrecortada, como el paso de un tren hacia la incógnita soledad de la noche. Están en torno mis cosas cotidianas: las paredes de una estancia vacía ${ }^{15}$.

La estancia vacía es un buen ejemplo de las relaciones existentes entre biografía y creación en la obra de Leopoldo Panero, característica que se puede hacer extensiva a los poemas de Escrito a cada instante, donde se despliegan los mismos temas que acabamos de enumerar. Así, la casa paterna es evocada en el soneto «Los pasos desprendidos», que Panero le dedica a su padre:

Golpea en el jardín la rota fuente; trepa la hiedra hacia la luz; los muros se alucinan, se tornan más oscuros, más altos de verdor contra el Poniente.

El silencio es mayor: sin ver, se siente la sombra en la pared: los ojos puros, los pasos desprendidos, inseguros, de mi padre al andar, como un relente.

Con hermosa quietud, entre sus ruinas transcurre entero el día, y la penumbra, la historia de las cosas, se deshace en ondas dulcemente vespertinas, mientras la casa dentro en paz se alumbra y el reloj nos silencia y nos desnace ${ }^{16}$.

Otros poemas de Escrito a cada instante, como los sonetos «A mis hermanas» ${ }^{17} \mathrm{y}$ «Epitafio a Dolores» ${ }^{18}$, también se encuentran íntimamente relacionados con el contenido de La estancia vacía, precedente inmediato de $L a$ casa encendida, obra que la crítica ha considerado casi unánimemente como la cima poética del grupo Escorial. En ella, Rosales logra convocar a los fantasmas del pasado en las habitaciones de su piso madrileño, que se van encendiendo y apagando conforme llegan y se marchan los espectros. La casa encendida inauguraba en la poesía española de posguerra el género del poema-libro de carácter narrativo y tema unitario. Consta de cinco estancias en verso libre precedidas por un «Zaguán» que adopta la forma del soneto. El título de cada una de las partes — no así el del «Zaguán», «Temblor junto a la memoria»- lo toma el granadino de sus poetas predilectos: «Ciego por voluntad y por destino" - Villamediana-, «Desde el umbral de un sueño me llamaron»-Antonio Machado-, «La luz del corazón llevo por guía» - Villamediana-, «Cuando a escuchar el alma me retiro» - conde de Salinas- y «Siempre mañana y nunca mañanamos» - Lope de Vega-.

Rosales, que se vale a lo largo de todo el libro de ciertos motivos recurrentes, va narrando una historia conforme avanzan los versos: la de su pasado, la de sus amigos, la de sus padres, la de la fiel criada Pepona... En la primera estancia, el yo del poema regresa a su casa y se detiene en la contemplación de los objetos que la pueblan, algunos de los cuales despiertan el recuerdo de su infancia en Granada. Al entrar en su cuarto, ya en la segunda estancia, observa que la luz de la habitación de enfrente está encendida, y se dirige a ella: «Es Juan Panero. Murió y era mi amigo» ${ }^{19}$. La tercera estancia está dedicada íntegramente a la figura de la amada — «te puse, para siempre, sobre los labios el nombre de María»20-, mientras que en la cuarta los protagonistas son los padres del poeta, Miguel Rosales y Esperanza Camacho, que se aparecen «en esta habitación donde los libros / caminan y caminan y caminan» ${ }^{21}$. El protagonista se encuentra con sus progenitores en el salón-biblioteca, y dicha aparición actúa como detonante del
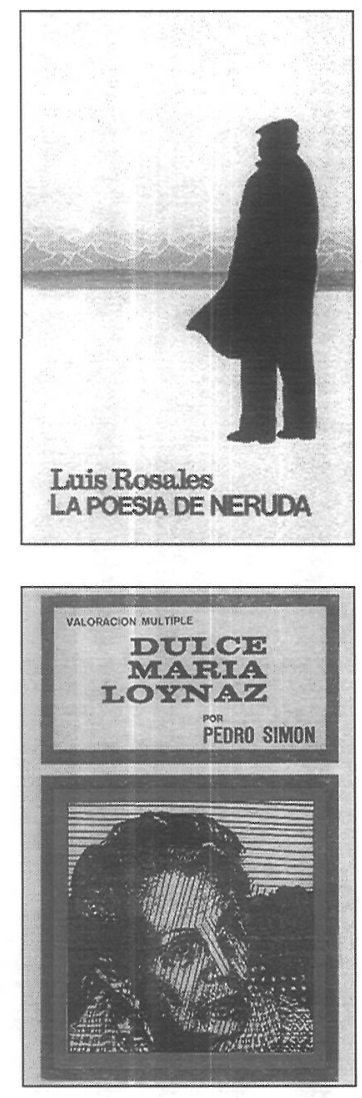

14 Escorial. Revista de culfura y letras, núm. 47, p. 72.

15

Ibid., p. 73.

16

Leopoldo Panero, Escrito a cada instante, Madrid, Cultura Hispánica, 1949, p. 99.

17

Ibid., p. 79.

18

lbid., p. 81

19

Luis Rosales, La casa encendida Madrid, Cultura Hispánica, 1949 , p. 42.

20

lbid., p. 75.

21

lbid., p. 84.

Tres variaciones sobre el tema de la casa: Leopoldo Panero, Luis Rosales y Dulce María Loynaz

JOAQUIN JUAN PENALVA 


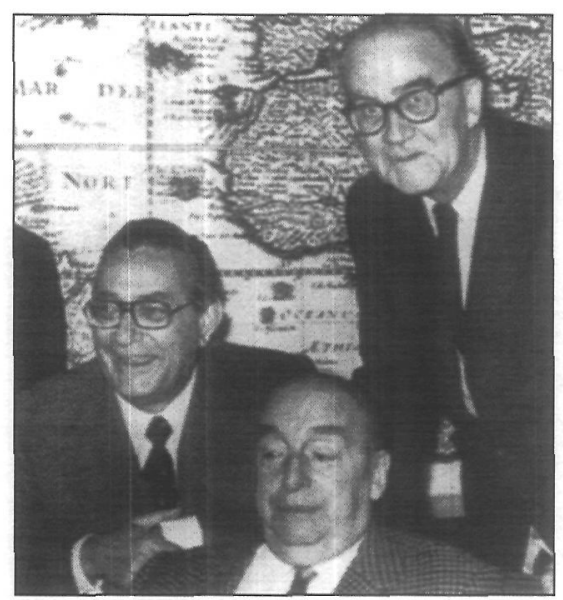

recuerdo: «después de quieta siempre, era tan buena, / tan ingenua de leche confiada, / que muchas veces las avispas se le quedaban quietas en las manos, / y ahora está en una cama de carne de hospital con el cuerpo en andrajos, / y vosotros sabéis, y Dios lo sabe, que se llamaba Pepa»22. La última estancia es, en realidad, una breve recapitulación o epílogo donde se recuperan algunos de los motivos dispersos a lo largo del texto y se encienden a un mis-

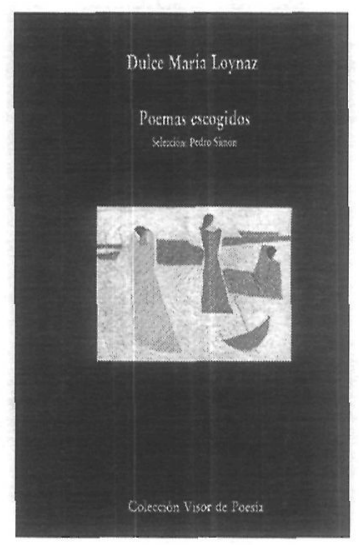

22

lbid., p. 98.

23

Ibid., p. 111

24

Mariano Brull, Poesía reunida, Madrid, Cátedra, 2000, p. 248.

25

Pedro Simón (ed.), Valoración múltiple. Dulce María Loynaz, La Habana, Casa de las Américas / Letras Cubanas, 1991, p. 61.

26

Efi Cubero, «Prólogo» a Dulce María Loynaz, últimos días de una casa, Madrid, Torremozas, 1993, p. 11.

Tres variaciones sobre el tema de la casa: Leopoldo Panero, Luis Rosales y Dulce María Loynaz

JOAQUÍN JUAN PENALVA mo tiempo todas las habitaciones de la casa. Después de un día fuera, el personaje Luis Rosales llega a la portería de su piso, donde le saluda el sereno. En ese momento, el poeta mira hacia arriba y ve que todas las ventanas exteriores están encendidas, y, tras los cristales, los fantasmas que han ido apareciéndose a lo largo de la composición le esperan ansiosos:

\section{Al día siguiente, -hoy-}

al llegar a mi casa -Altamirano, 34- era de noche, y quién te cuida, ¿dime?; no llovía;

el cielo estaba limpio;

- «Buenas noches, don Luis» —dice el sereno,

y al mirar hacia arriba,

vi iluminadas, obradoras, radiantes, estelares,

las ventanas,

-sí, todas las ventanas-;

Gracias, Señor, la casa está encendida 23.

Tanto en La estancia vacía como en $L a$ casa encendida el yo poemático se puede asimilar a la voz del poeta. En el caso de Panero, esa identificación es implícita, pero no en el de Rosales, ya que el poeta granadino aparece explícitamente con su nombre en diferentes ocasiones. De igual modo, ambos poemas están poblados por fantasmas del pasado $y$, si bien la casa actúa como la argamasa que une los diferentes episodios biográficos, en ninguno de los dos se le concede el protagonismo absoluto, algo que sí ocurre en Últimos dias de una casa, de Dulce María Loynaz.

No caeré en el error de afirmar que el motivo de la casa lo tomó la autora cubana de Rosales o de Panero, ya que existían en la tradición poética cubana importantes precedentes del mismo. El más importante era el poema «La casa del silencio», incluido en el poemario homónimo de Mariano Brull, publicado en 1916. Últimos dias de una casa bebía directamente de aquella composición, que trataba sobre la decadencia de una mansión de antiguo abolengo y cuyos primeros versos rezaban así:

Hace mucho tiempo fue la casa en fiesta; cantaba el Pan griego la buena canción; músicas agrestes trajo la floresta y soplaron auras de amor y pasión.

Todo alli era ruido y danzas y trinos; lucía el jacinto su antiguo esplendor; era dulce y honda la voz de los pinos; bullía la tierra con vehemente ardor.

El bosque vibraba de contento y vida, el sagrado bosque era un corazón; corazón opreso de ansia sin medida y poblado de almo sueño de ilusión $n^{24}$.

Paradójicamente, el poema-libro de Loynaz fue publicado por primera vez en España en 1958 - la fecha del colofón resultaba muy significativa: 31 de diciembre-, siendo prácticamente desconocido para el público cubano hasta que en 1984 fue recogido en las Poesías escogidas publicadas en La Habana. Se había encargado de su edición Antonio Oliver, que también firmaba el prólogo. El resultado fue un opúsculo de treinta y una páginas, de tirada bastante breve, que se incluyó en la Serie Americana de la Colección Palma. La propia Loynaz ha opinado que «si se considera como poema aislado, es posiblemente lo mejor que he escrito. En cuanto su motivación, yo misma no lo sé. Si creyera en las premoniciones, podría pensar que fue una de ellas, porque yo estaba destinada a asistir a la dolorosa destrucción de una casa. Pero cuando escribí el poema no podía saberlo» 25 .

Últimos días de una casa es un extenso poema en tres tiempos que recorre la vida de la familia Loynaz a través de la perspectiva de la casa, que, a lo largo de toda la composición, habla en primera persona. Se trata de la misma casa-palacio que encontramos en la novela lírica Jardin. Según Efi Cubero, la casa «parece nutrirse de su propia leyenda, en sus propias historias detenida. En ella siguen viviendo los personajes que una vez la habitaron, fantasmas de otro tiempo que presiden las estancias prisioneros de un mundo que se aleja irremediablemente» ${ }^{26}$. El poema consta de sesenta y ocho tiradas de versos que suman 
un total de quinientos veintiuno. La autora se vale del verso libre, al igual que hiciera Rosales en La casa encendida. La propia mansión familiar actúa como portavoz de las opiniones de Dulce María Loynaz. Ha sido abandonada por sus habitantes, de ahí que en su interior predomine el silencio: «No sé por qué se ha hecho desde hace tantos días / este extraño silencio" 27 . Esta circunstancia contrasta con el pasado esplendoroso de la casa, cuando siempre estaba poblada y llena de alegría:
Nadie puede decir
que he sido yo una casa silenciosa;
por el contrario, a muchos muchas veces
rasgué la seda pálida del sueño
-el nocturno capullo en que se envuelven-
con mi piano crecido en la alta noche,
las risas y los cantos de los jóvenes
y aquella efervescencia de la vida
que ha barbotado siempre en mis ventanas
como en los ojos de
las mujeres enamoradas ${ }^{28}$.

No era ésta la primera vez que la casa estaba sola, pero entonces, a diferencia de ahora, ese silencio «provenía de 'ellos', / los que dentro de mí partían el pan»29. El silencio humano de los tiempos pasados venía motivado por la ausencia temporal o por la tristeza, pero no por la absoluta soledad. La casa se considera a sí misma vieja, y, por tanto, sufre alguno de los achaques propios de la edad. Ha visto desaparecer a su alrededor a sus contemporáneas, que han sido sustituidas por edificios modernos: «poderosos los flancos, / alta y desafiadora la cerviz»30. Las «intrusas» se han ido apoderando del paisaje, robándole el sol, los pájaros y el mar, antiguo compañero de días y noches.

Pronto empieza para la casa la fuga inexorable de los objetos que precede a los preparativos finales. Los muebles, algunos de ellos arraigados ya en los muros, dejan la mancha de su ausencia sobre la pintura o el papel de las paredes: «Son manchas que persisten y afectan vagamente / las formas desaparecidas, / y me quedan igual que cicatrices / regadas por el cuerpo»31. La protagonista se cree maldita, enferma, leprosa... Los mangos del patio se precipitan maduros al suelo sin que nadie los tome para saborearlos; una ventana abierta del comedor permite que los murciélagos accedan por la noche al recinto, pero ella no se da cuenta de lo que ocurre. De su tiempo únicamente queda la campana de la iglesia, que en el momento del poema da las tres, y sirve para recordar esa misma hora, pero muchos años atrás, cuando la madre se sentaba a coser con sus hijas.

En la tirada treinta y ocho se produce una inflexión en el poema, ya que se cierra el período de evocación y se recupera momentáneamente a los habitantes de la casa:

Las tres era la hora en que...

¡La puerta!

¡La puerta que ha crujido abajo!

¡La están abriendo, sí!... La abrieron ya.

Pisadas en tropel avanzan, suben...

¡Ellos han vuelto al fin! Yo lo sabía;

yo no he dejado un día de esperarlos...

¡Ay frutas que granar en mis frutales!

¡Ay campana que suenas otra vez

la hora de mi dicha!32

Pero la dicha dura apenas una hora. Cuando la protagonista reemprende su discurso, ya se han marchado de nuevo sus habitantes, que tan sólo habían vuelto para recoger algún objeto olvidado. La casa cifra sus esperanzas en la próxima Nochebuena, y recuerda la del año anterior, cuando ya se intuía la tristeza y la soledad que ahora la asolaban. Al llegar a las últimas tiradas de versos, interrumpe su relato y se declara portadora de alma:

\section{La Casa, soy la Casa.}

Más que piedra y vallado,

más que sombra y que tierra,

más que techo y que muro,

porque soy todo eso, y soy con alma33.

Al reanudar la historia, un nuevo día amanece y trae consigo nuevos hombres que la casa no había visto antes. Todavía no se quiere dar cuenta de lo que ocurre, pero el desenlace ya está muy próximo. De repente, el jardín se ha llenado de extraños, "hombres con sus torsos desnudos / y sus picas en alto ${ }^{34}$. Al final lo comprende todo, mientras esos extraños hacen de sus paredes polvo y de sus cristales añicos:

¡Ahora es que trago la verdad de golpe!

¡Son los hombres, los hombres,

los que me hieren con sus armas!

Los hombres de quienes fui madre

sin ley de sangre, esposa sin hartura

de carne, hermana sin hermanos,

hija sin rebeldía.

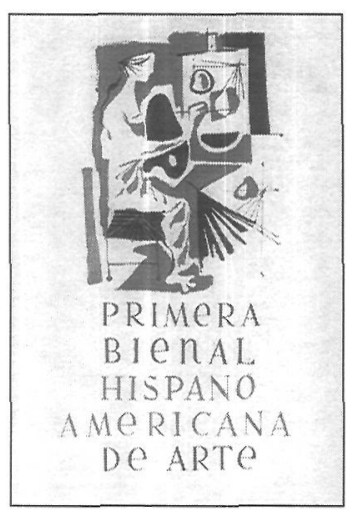

27

Ibid., p. 27

28

Ibid.

29

1bid., p. 28

30

Ibid., p. 29

31

Ibíd., p. 33.

32

Ibid., p. 36

33

Ibid., pp. 40-41.

34

Ibid., p. 42.
Tres variaciones sobre el tema de la casa: Leopoldo Panero, Luis Rosales y Dulce María Loynaz

JOAQUÍN JUAN PENALVA 
Tres variaciones sobre el tema de la casa: Leopoldo Panero, Luis Rosales y Dulce María Loynaz

JOAQUÍN JUAN PENALVA
Los hombres son y sólo ellos,

los de mejor arcilla que la mía,

cuya codicia pudo más

que la necesidad de retenerme.

$Y$ fui vendida al fin,

porque llegué a valer tanto en sus cuentas,

que no valía nada en su ternura...

Y si no valgo en ella, nada valgo...

$\mathrm{Y}$ es hora de moriri ${ }^{35}$.

El gran mérito de Loynaz en Últimos dias de una casa es haber conseguido dotar de espíritu a su creación, del mismo modo en que Panero y Rosales elevaban a categoría poética los sucesos más triviales de su existencia. La casa de la escritora cubana se contagia del alma de sus inquilinos. Últimos días de una casa es, en realidad, el canto a una forma de vida que se ha perdido, la de la vivienda familiar donde conviven varias generaciones. Por ella desfilan padres y hermanos, pero también la propia autora y el espíritu de la hermana difunta, la eterna pequeña, porque murió siéndolo. Lo ritual, lo ceremonial y lo cotidiano forman parte de la vida de esa familia en una mansión de La Habana, a cuya ruina, tristeza y dispersión familiar nos ha sido dado asomarnos.

Tanto La casa encendida y La estancia vacía como Últimos días de una casa hacen suyo un modelo muy cultivado en la lírica anglosajona, el del poema unitario o poemalibro, con un recorrido argumental que va ahilando una historia, aunque sin renunciar por ello a los recursos propios de la poesía. Rosales y Panero relataban la suya a partir de los propios recuerdos y evocaciones, partiendo de la intimidad del yo; Loynaz da un salto cualitativo y narra la historia de su familia a través de las ventanas de la mansión familiar. En los tres casos se trata de lo real cotidiano elevado a la categoría de arte. Una vez más, la vida convertida en literatura.

\section{BIBLIOGRAFÍA}

BRULL, Mariano, Poesía reunida, Madrid, Cátedra, 2000.

CANO, José Luis, «Los libros del mes: Leopoldo Panero, Escrito a cada instante; Luis Rosales, La casa encendida; José María Valverde, La espera», Insula, Madrid, núm. 43, 15 de julio de 1949, pp. 4-5.
DÍAZ DE ALDA SAGARDÍA, María del Carmen, La poesía de Luis Rosales (desde el inicio a La casa encendida): de la biografía a la poética, Madrid, Universidad Complutense, 1989.

Espadaña. Revista de poesía y crítica, edición facsimilar, León, Ayuntamiento de León, 1978.

GULLÓN, RICARDO, La juventud de Leopoldo Panero, León, Diputación Provincial de León, 1985.

HORNO-DELGADO, Asunción, Margen acuático: Poesía de Dulce María Loynaz, Gijón, Júcar, 1998.

HUERTA CALVO, Javier, De poética y politica. Nueva lectura del Canto personal de Leopoldo Panero, León, Diputación Provincial de León/Instituto Leonés de Cultura, 1996.

LOYNAZ, Dulce María, Antología lírica, Madrid, Espasa-Calpe, 1993, 2a edición.

- Ensayos literarios, Salamanca, Universidad de Salamanca, 1993.

- (1951), Jardín. Novela lírica, Barcelona, Seix Barral, 1993.

- Poemas escogidos, Madrid, Visor, 1995, $2^{\text {a }}$ edición.

- Poemas náufragos, Cádiz, Diputación Provincial de Cádiz, 1992.

- Últimos días de una casa, Madrid, Torremozas, 1993.

- Yo fui (feliz) en Cuba... Los días cubanos de la infanta Eulalia, La Habana, Letras Cubanas, 1993.

NÚÑEZ, Ana Rosa (ed.), Homenaje a Dulce María Loynaz, Miami, Universal, 1993.

PANERO, Leopoldo, (1973), Antología, edición de Juan Luis Panero, Barcelona, Plaza \& Janés, 1977.

- Antología de la poesía bispanoamericana. Desde sus comienzos hasta Rubén Darío. Tomo I, Madrid, Editora Nacional, 1944.

- Antologia de la poesía hispanoamericana. Desde Rubén Dario hasta nuestros días. Tomo II, Madrid, Editora Nacional, 1945.

- Canto personal. Carta perdida a Pablo Neruda, Madrid, Cultura Hispánica, 1953.

- Escrito a cada instante, Madrid, Cultura Hispánica, 1949.

- Escrito a cada instante, Madrid, Bullón, 1963.

- Obras Completas. Volumen I. Poesías (1928-1962), edición de Juan Luis Panero, Madrid, Editora Nacional, 1973. 
- Obras Completas. Volumen II. Prosa, edición de Juan Luis Panero, Madrid, Editora Nacional, 1973.

- Por donde van las águilas, Granada, Comares, 1994.

ROSALES, LUIS, La casa encendida, Madrid, Cultura Hispánica, 1949.

- La poesia de Neruda, Madrid, Editora Nacional, 1978.

- Obras completas I. Poesía, Madrid, Trotta, 1996.
SIMÓN, Pedro (ed.), Valoración múltiple. Dulce María Loynaz, La Habana, Casa de las Américas/Letras Cubanas, 1991.

VIVANCO, Luis Felipe, «Aproximándome a la poesía temporal y realista», Proel, VI, primavera-estío de 1950, pp. 17-27.

- Introducción a la poesía española contemporánea 2, Madrid, Guadarrama, 1971, $2^{a}$ edición.

- "La palabra encendida», Cuadernos Hispanoamericanos, Madrid, núm. 9, mayojunio de 1949, pp. 723-733. 